\title{
Mathematical Modelling and Volume Prediction of Metal Melted by Electron Beam Welding in Copper and Stainless Steel 304 Dissimilar Metal Joints
}

\author{
R. Ajith Raj, M. Dev Anand, S. Ramabalan
}

\begin{abstract}
Industries such as Aircraft manufacturing, nuclear power plants and oil refineries witness a wide range of applications in dissimilar welded joints considering the advantage of strength and high corrosion resistance. The primary objective of this research is to study the dissimilar metal joints of pure Copper and Stainless Steel 304 using Electron Beam Welding for nuclear power plant applications. The various physical properties of both metal varies. Joining of copper is also not feasible by using existing welding methods due its high thermal conductivity and subsequently joining of these dissimilar materials is more complex. Electron Beam welding is a useful method in joining such dissimilar metal combinations. The heat generated by the electron beam melts the metals in different ratios because of the difference in the melting point of metals. Even though various researches has been focused in the area of dissimilar metal joints, no researcher worked to predict the heat energy rate of electron beam and the melting volume of metals. In this work, the volume of copper melted and volume of Stainless Steel 304 melted with respect to the heat generation has been found out by means of numerical calculations. The distribution of heat in both metals is also found using ANSYS software. A mathematical model is also created using MINITAB software and the volume of copper and Stainless Steel 304 melted with respect to the heat energy is predicted.
\end{abstract}

Keywords--- Electron Beam Welding, Dissimilar Metal Joints, Copper, Stainless Steel 304.

\section{INTRODUCTION}

The use of Electron beam for metal joining has augmented in the present days due to its fastest rate knotted with the quality standards of industries. Steam of electrons are accelerated to a velocity approximately equal to two third the speed of light. This focussed electrons with high velocity losses its Kinetic energy upon collision with the metal to be welded and converts in to heat energy resulting in fusion or melting of the two metal parts to be welded.

In electron beam welding the fusion zone and the heat affected zone are very narrow when compared with other welding techniques. The deep penetration, low distortion, controlled repeatability, high welding rate achieved by electron beam are added advantages to this technique. Since the welding is carried out in a vacuum chamber the contaminations in welding is totally supressed. The heat

Revised Manuscript Received on July 10, 2019.

R. Ajith Raj, Assistant Professor and Head, Department of Aeronautical Engineering, Noorul Islam Centre for Higher Education, Kumaracoil, Kanyakumari District, Tamil Nadu, India. (e-mail: ajithraj006@gmail.com)

M. Dev Anand, Professor and Director Research, Department of Mechanical Engineering, Noorul Islam Centre for Higher Education, Kumaracoil, Kanyakumari District, Tamil Nadu, India.

S. Ramabalan, Principal and Professor, Department of Mechanical Engineering, E.G.S. Pillay Engineering College, Nagapattinam, Tamil Nadu, India. energy produced is a function of beam current, beam Voltage and welding time. If the heat energy produced is just sufficient to melt the metal and no heat energy is transferred to the un-melted base metal then the weld is free from buckling, wrapping, undesirable grain growth and metallurgical transformations. In Electron beam welding heat can be controlled and the heat energy required for welding is much lesser when compared with other welding methods.

In case of dissimilar metal joints, due to the difference in melting point, thermal conductivity and density, the volume of two metals melted differs with respect to the corresponding heat generated. The parameters responsible for the net heat generated are modified with nine set of values. The heat generated, rate of heat, time taken to weld, volume of copper welded and volume of Stainless steel 304 melted for each set of values are calculated numerically from the basic heat balancing equations of fusion welding [1]. Copper and Stainless Steel 304 both of size 100mm X $60 \mathrm{~mm}$ X $6 \mathrm{~mm}$ is taken for the study as shown in Figure 1.

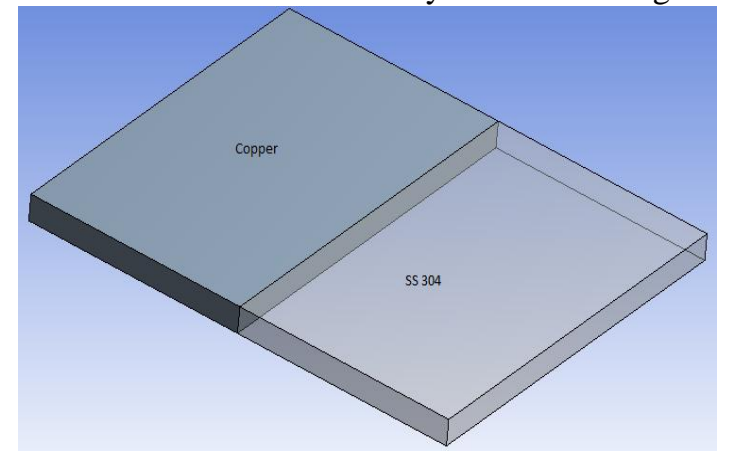

Figure 1: Butt Joint Welding Specimen

The weld is assumed to be a closed square butt joint. The influence of current and voltage for heat generation and its impact on the volume of metal melted has been discussed in detail. The distribution of heat in both metals is also studied by a simulation using ANSYS software.

\section{LITRATURE REVIEW}

G. Metzger and R. Lison [2] studied the weldability of dissimilar metal joints with Thirty-three two-member combinations of dissimilar metals. Metallographic examination, tensile tests and bend tests were carried out in the welded specimen. 


\section{Mathematical Modelling and Volume Prediction of Metal Melted by Electron Beam Welding in Copper and Stainless Steel 304 Dissimilar Metal Joints}

From the above tests assured exceptional characteristics of the electron beam welding process such as narrow fusion zone and the ability to pinpoint the weld exactly, have recognized to be the advantages for the welding of dissimilar metals.

R. Rai, T. A. Palmer, J. W. Elmer, and T. Debroy [3] had developed a numerical model for three-dimensional heat transfer and fluid flow in keyhole mode electron beam welding for $304 \mathrm{~L}$ stainless steel welds made at different power densities.

The geometry of the keyhole made during electron beam welding was designed through an energy balance at the keyhole walls. This model is used to calculate the threedimensional temperature field and fluid velocities for electron beam welding of 304L stainless steel.

Miroslav Sahul, Martin Sahul, Milan Turna, Paulina Zackova [4] studied the disk Laser Welding of Copper to Stainless Steel. The concentration of copper decreases in the direction from copper sheet towards the fusion zone. Contrary, the concentrations of $\mathrm{Fe}, \mathrm{Cr}$ and $\mathrm{Ni}$ increase in the direction from fusion zone towards austenitic stainless steel side.

K. K. Kanaujia , M. P. Rout, B. C. Behera, S. K. Sahoo, B. K. Maharana [5] optimized the tensile Strength of AISI304 Stainless Steel and Copper using Laser Welding. Parameters such as laser power, welding speed and pulse duration were considered for the study. Taguchi approach was used for the selected factors and the Joint strength was determined using the universal testing machine.

T.A. Mai, A.C. Spowage [6] Characterized the dissimilar joints in laser welding of Steel- Kovar, Copper-Steel and Copper-Aluminium using laser welding. The results of this experiment shows that Melting ratio can play important role in defect free welding of dissimilar metal weld joint. So that heat distribution per unit area should be control and the formation of brittle inter-metallic phases could be avoided.

Rakesh Chaudhari, Riddhish Parekh, and Asha Ingle [7] reviews different methods used to join dissimilar metals with particular focus to reduce sharp changes in composition and properties of the metals being joined.

A review on fusion welding processes for dissimilar metal joints is observed. With an expenditure of MIG welding, the banded microstructure of copper and iron is observed near the interface.

Due to different melting point, MIG does not consent copper to melt with iron, which leads to penetration.

P. Lacki, K. Adamus, K. Wojsyk, M. Zawadzki, Z. Nitkiewicz[8] studied the thermo-mechanical analysis of Inconel 706 tube using electron beam welding. The goal of the work was to design EBW that will produce $\mathrm{FZ}$ of required depth.

PLS method was compared to OLS method. It was shown that while OLS method gives better results for training data PLS might be more accurate for test data.

From the above literature study it was observed that most of the researchers have used laser beam welding for dissimilar metal joints and very few have used Electron Beam welding.

But till now no researcher tried to numerically evaluate the metal melting volume in dissimilar metals using Electron beam welding is performed under vacuum conditions and it has much advantages over the other welding techniques.

\section{NUMERICAL CALCULATIONS}

The important physical properties responsible for melting of copper and stainless steel 304 are as shown in Table 1.

Table 1: Physical Properties of Copper and Stainless Steel 304

\begin{tabular}{|c|c|l|l|l|}
\hline Metals & $\begin{array}{l}\text { Density } \\
(\mathrm{Kg} / \mathrm{m} 3)\end{array}$ & $\begin{array}{l}\text { Melting } \\
\text { Point } \\
(\mathrm{K})\end{array}$ & $\begin{array}{l}\text { Specific } \\
\text { Heat } \\
(\mathrm{J} / \mathrm{Kg} \mathrm{K})\end{array}$ & $\begin{array}{l}\text { Thermal } \\
\text { Conductivity } \\
(\mathrm{W} / \mathrm{m} \mathrm{K})\end{array}$ \\
\hline Copper & 8940 & 1356 & 376.812 & 385 \\
\hline SS 304 & 7850 & 1723 & 530 & 16.2 \\
\hline
\end{tabular}

From the above table it is clear that both metals experiences difference in melting point, density and thermal conductivity.

To join these two metals heat is required to increase the temperature of solid metal to its melting point at which the solid phase of metal is transformed to liquid phase.

The amount of heat energy required for melting the given volume copper and stainless steel 304 is given by

$$
\begin{aligned}
\mathrm{U}_{\text {Copper }} & =\mathrm{KT}_{\text {Copper }}^{2} \\
\mathrm{U}_{\text {SS 304 }} & =\mathrm{KT}_{\mathrm{SS} 304}^{2}
\end{aligned}
$$

Where, $\mathrm{U}_{\text {Copper }}$ and $\mathrm{U}_{\mathrm{SS} 304}$ are unit energy for melting copper and Stainless Steel 304.

$\mathrm{T}_{\text {Copper }}$ and $\mathrm{T}_{\mathrm{SS} 304}$ are the melting points of copper and Stainless Steel 304

$\mathrm{K}$ is a constant and its value is $3.33 \times 10-6$

$$
\begin{aligned}
& \mathrm{U}_{\text {Copper }}=3.33 \times 10^{-6} \times 1356^{2}=6.122990 \mathrm{~J} / \mathrm{mm}^{3} \\
& \mathrm{U}_{\mathrm{SS} 304}=3.33 \times 10^{-6} \times 1723^{2}=9.885867 \mathrm{~J} / \mathrm{mm}^{3}
\end{aligned}
$$

The net heat energy used for the welding operation can be derived from the below equation.

$$
\mathrm{H}_{\mathrm{W}}=\mathrm{U}_{\text {mtael }} \times \mathrm{V}_{\text {mtael }}
$$

Where $V_{\text {metal }}$ is the volume of metal melted in $\mathrm{mm}^{3}$.

Therefore the heat energy required for melting copper and stainless steel is

$$
\begin{gathered}
\text { for copper , } \mathrm{H}_{\mathrm{W}}=\mathrm{U}_{\text {copper }} \times \mathrm{V}_{\text {copper }} \\
\text { for SS 304, } \mathrm{H}_{\mathrm{W}}=\mathrm{U}_{\mathrm{SS} 304} \times \mathrm{V}_{\mathrm{SS} 304}
\end{gathered}
$$

Since the values of current, voltage and speed of electron beam are known the Heat energy available in Joules can be calculated as

$$
\mathrm{H}_{\mathrm{W}}=\text { Current } \mathrm{x} \text { Voltage } \mathrm{x} \text { time }
$$

To predict the volume of copper and stainless steel melted at different values of heat input by varying current and speed, a design of experiment was implemented using Taguchi approach and a mathematical model is developed using response surface method.

This model is also used to forecast the influence of heat input on metal melting volume.

The Input and Output values of Electron Beam Welding are shown in Table 2. 
Table 2: Input and Output values of Electron Beam Welding

\begin{tabular}{|c|c|c|c|c|c|c|}
\hline \multirow[b]{2}{*}{$\begin{array}{l}\text { Sl. } \\
\text { No } \\
\text {. }\end{array}$} & \multicolumn{3}{|c|}{ INPUT } & \multicolumn{3}{|l|}{ OUTPUT } \\
\hline & $\begin{array}{l}\text { Heat } \\
\text { Energ } \\
\text { y Rate } \\
\text { ( EI) } \\
\mathrm{J} / \mathrm{s}\end{array}$ & $\begin{array}{l}\text { Spee } \\
\mathrm{d} \\
\mathrm{mm} / \\
\mathrm{s}\end{array}$ & $\begin{array}{l}\text { Work } \\
\text { Distanc } \\
\text { e mm }\end{array}$ & $\begin{array}{l}\text { Heat } \\
\text { Generate } \\
\text { d Joules }\end{array}$ & $\begin{array}{l}\text { VCoppe } \\
\text { r mm3 }\end{array}$ & $\begin{array}{l}\text { VSS } \\
304 \\
\text { mm3 }\end{array}$ \\
\hline 1. & 600 & 8 & 100 & 7500 & 1224.89 & 758.65 \\
\hline 2. & 600 & 24 & 260 & 2500.2 & 408.32 & 252.90 \\
\hline 3. & 600 & 40 & 425 & 1500 & 244.97 & 151.73 \\
\hline 4. & 1800 & 8 & 100 & 22500 & 3674.6 & 2275.97 \\
\hline 5. & 1800 & 24 & 260 & 7500.6 & 1224.98 & 758.71 \\
\hline 6. & 1800 & 40 & 425 & 4500 & 734.935 & $\begin{array}{l}455.195 \\
6 \\
\end{array}$ \\
\hline 7. & 3000 & 8 & 100 & 37500 & 6124.45 & $\begin{array}{l}3793.29 \\
6\end{array}$ \\
\hline 8. & 3000 & 24 & 260 & 12501 & 2041.64 & 1264.53 \\
\hline 9. & 3000 & 40 & 425 & 7500 & 1224.89 & 758.65 \\
\hline
\end{tabular}

The above calculated output shows that the volume of two metals melted differs with respect to the corresponding heat generated. It shows that for all the nine set of values the volume of copper melted is more than that of the stainless steel.

\section{MATHEMATICAL MODELLING}

Three Mathematical models has been created using RSM, a statistical technique by which the correlation between the response and variables can begenerated. One for the net heat energy generated with respect to the heat energy rate, speed and distance of work from the electron gun. Other two models are for volume of melted in Copper and Stainless Steel 304 respectively.

Heat Generated $=0.000000-9.998 \mathrm{EI}+0.000000$ Speed 0.000000 Work Distance - 0.000000 EI*EI - 13.85 EI*Speed + 1.333 EI*Work Distance

$$
\mathrm{S}=0 \text { R-sq. }=100 \% \quad \text { R-sq. }(\text { adj. })=100 \%
$$

$\mathrm{Vcu}=0.051-1.63284 \mathrm{EI}+0.024$ Speed -0.0023 Work Distance + 0.000000 EI*EI - 2.26243 EI*Speed + 0.217737 EI*Work Distance

$$
\begin{aligned}
& \mathrm{S}=0.0342377 \mathrm{R} \text {-sq. }=100.00 \% \text { R-sq. }(\text { adj. })=100.00 \% \\
& \text { Vss }=-0.0437-1.01128 \mathrm{EI}-0.0152 \text { Speed }+0.00154 \\
& \text { Work Distance }+0.000000 \mathrm{EI} * \mathrm{EI}
\end{aligned}
$$$$
\text { -1.40127 EI*Speed + 0.134859 EI*Work Distance }
$$$$
\mathrm{S}=0.0045986 \text { R-sq. }=100.00 \% \text { R-sq. }(\text { adj. })=100.00 \%
$$

\section{RESULTS AND DISCUSSIONS}

The net heat energy generated, volume of metal melted in copper and Stainless Steel 304 has been found out using Numerical calculations. The values are analysed and studied at nine different current and welding speeds.

\subsection{Effect of Current and Speed on Heat Generation}

The rate of heat flow which is a function of current and voltage has a great impact on the net heat generated with respect to the speed. A contour has been created for the heat generated representing the nine set of values for the current and speed. By analysing this contour the impact of these values on the net heat generated can be assumed. Contour plot of Heat Generated Vs Speed, EI is shown in Figure 2.

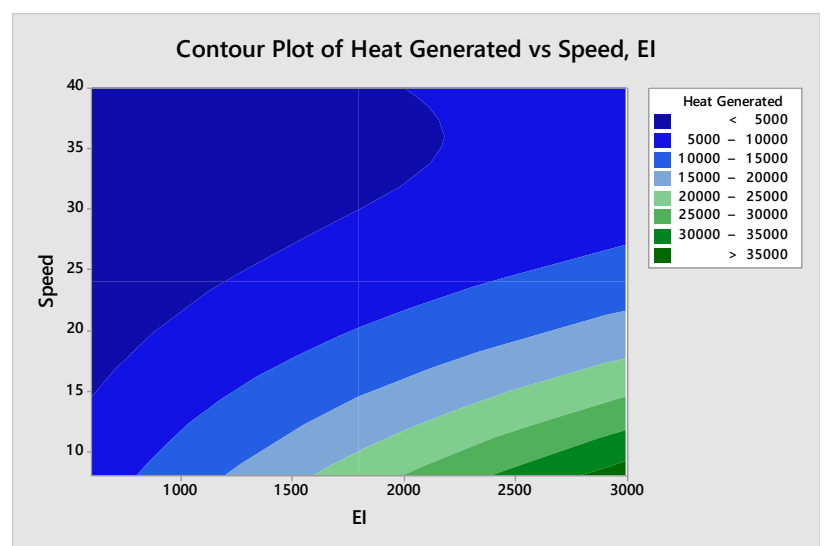

Figure 2: Contour plot of Heat Generated Vs Speed, EI

It was found that the net heat generated is maximum when the speed is less and the rate of heat energy is maximum. Similarly, the heat energy is least at maximum speed and low values of heat energy rate.

\subsection{Effect of Speed on Melting of Copper and SS 304}

The net heat energy generated is maximum at low speed of welding. Thus the speed has a great impact on the heat generation which in turn has impact on the melting of the metals. A contour has been created to study the effect of speed on the melting of copper and stainless steel 304. Contour plot of Volume of Copper and Stainless steel melted with respect to speed is shown in Figure 3.

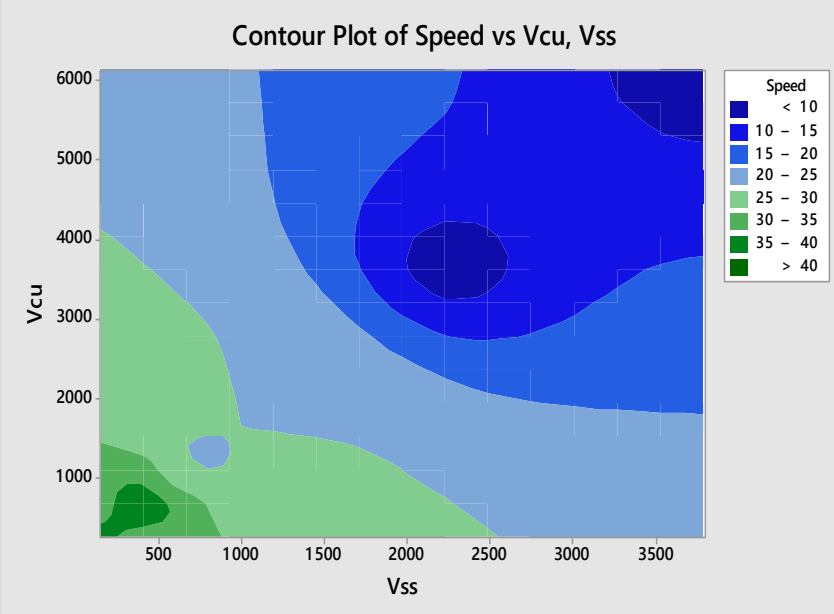

Figure 3: Contour plot of Speed Vs Volume of Copper and Stainless steel melted

From this plot it can be determined that when the speed is very low the volume of copper melted is more associated to that of the volume of Stainless Steel 304 melted. This is due to the high generation of heat energy at low speed.

\subsection{Effect of Heat on Melting of Copper and SS 304}

Due to the difference in melting point, thermal conductivity and density, the volume of two metals melted differs with respect to the corresponding heat generated. Various plots have been created with nine set of values of heat generated to study the volume of copper melted and volume of Stainless steel melted. Contour plot of Heat Generated Vs Speed, EI is shown in Figure 4. 


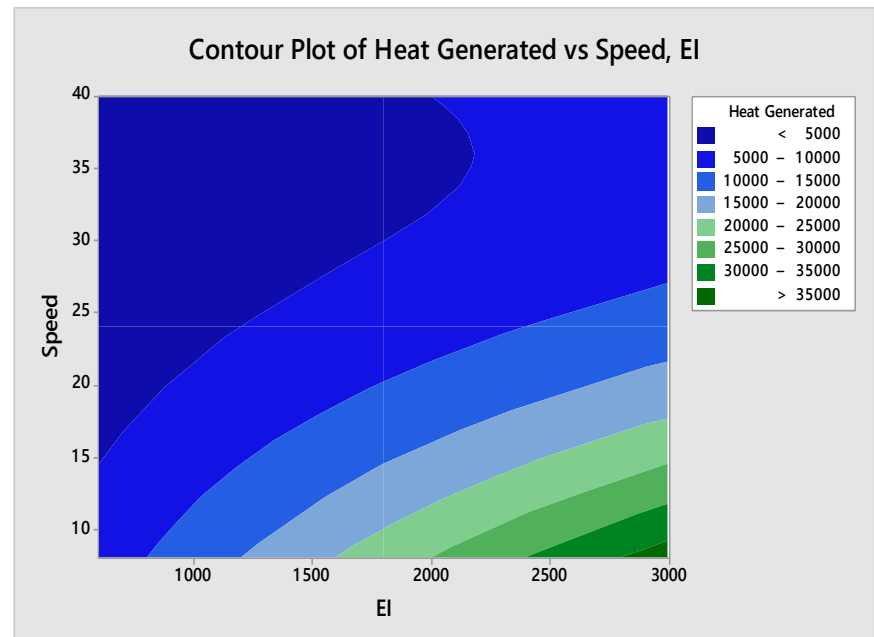

Figure 4: Contour plot of Heat Generated Vs Speed, EI

The Volume of Copper and Stainless steel melted with respect to heat generated has been represented in bar and time series plot as shown in Figure 5 and Figure 6.

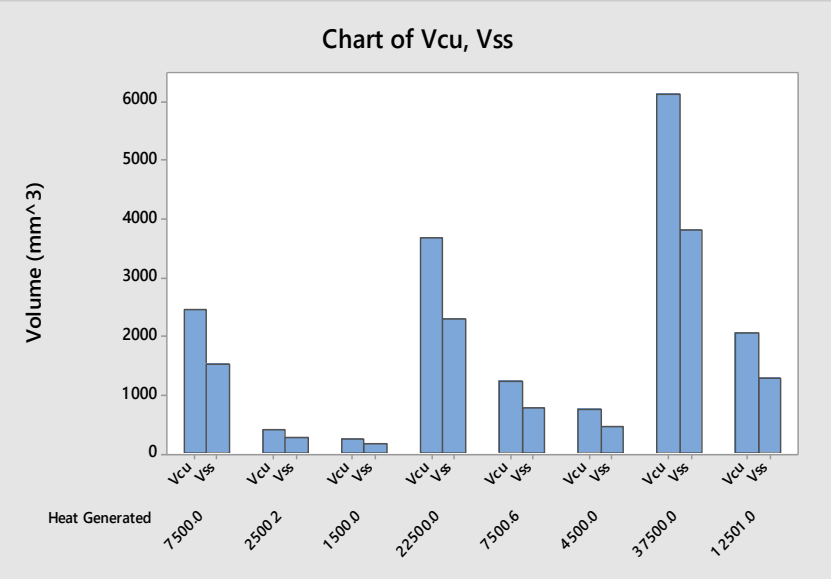

Figure 5: Bar Chart Representing Heat generated Vs Volume of Copper and Stainless Steel Melted

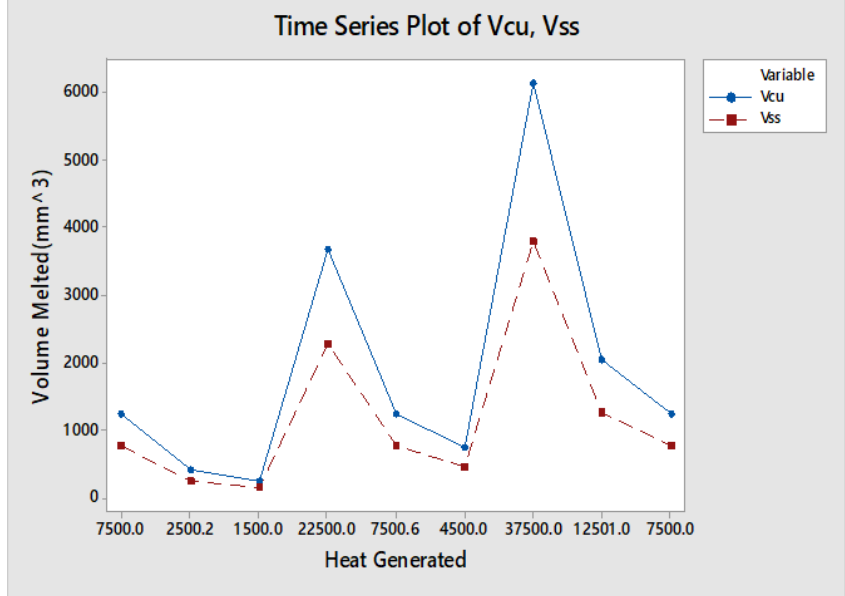

Figure 6: Time Series Chart Representing Heat generated Vs Volume of Copper and Stainless Steel

By analysing the above three plots it was found that for all values of heat generated, copper melts more than that of the stainless steel. This is due to the high thermal conductivity of copper.

\subsection{Distribution of Heat in Copper and Stainless Steel 304}

To study the distribution of heat on both metals a software analysis has been carried out for a single set of values of input using ANSYS software and is shown in
Figure 7. From the above plot it was found that the heat transfer is more in copper than that of the Stainless Steel 304. This is also due to the difference in thermal conductivity on both metals.

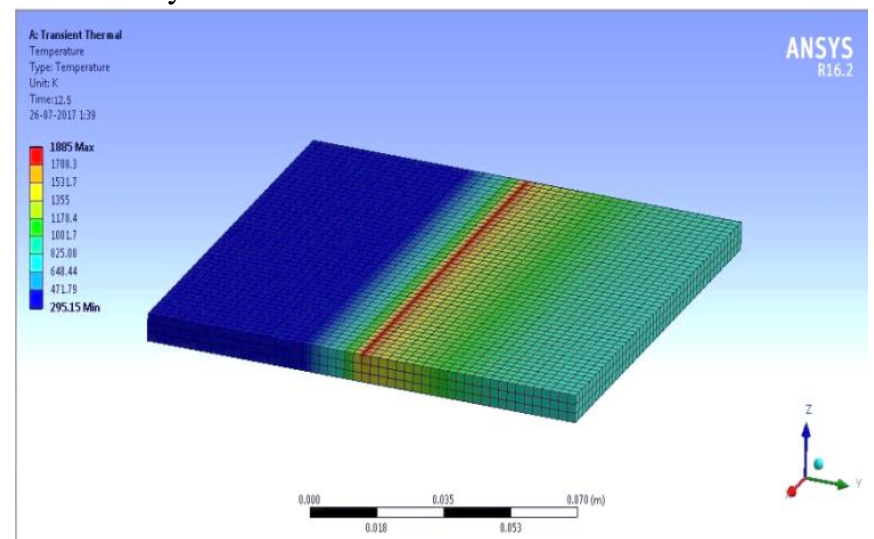

Figure 7: Distribution of Heat in Copper and Stainless Steel 304 using ANSYS

\section{CONCLUSION}

In this paper numerical calculations have been carried out using the basic heat balance equations of fusion welding to find the volume of metal melted using electron beam welding in dissimilar metal joints of Copper and Stainless Steel 304. The parameters like current, voltage, welding speed and its effect on the heat energy generation are studied. A mathematical model is also created using MINITAB software and the volume of copper and Stainless Steel 304 melted with respect to the heat energy is predicted. It was noted that the volume of metal melted is more on copper side than that of SS side at all values of heat. The distribution of heat in both metals is also found using ANSYS software.

\section{ACKNOWLEDGEMENT}

The authors would also like to express their gratitude to Noorul Islam Centre for Higher Education for the facilities provided during the research.

\section{REFERENCES}

1. Mikell P. Groover "Fundamentals of Modern Manufacturing: Materials, processes and Systems", John Wiley \& Sons, Inc., Prentice-Hall, New Jersey, New York.

2. Metzger G. and R Lison, "Electron beam welding of dissimilar metals" Welding J, Vol. 55, no.8, pp. 230240, 1976.

3. Rai R., TA Palmer, JW Elmer, and T Debroy, "Heat transfer and fluid flow during electron beam welding of 304L stainless steel alloy", Welding Journal, Vol. 88, no.3, pp. 54-61, 2009.

4. Sahul Miroslav., Milan Turna, and Paulina Zackova, "Disk Laser Welding of Copper to Stainless Steel", Advanced Materials Research, Vol. 1077, pp. 76-81, 2014. 
5. K. K. Kanaujia , M. P. Rout, B. C. Behera, S. K. Sahoo, B. K. Maharana, "Optimization of Tensile Strength of AISI304 Stainless Steel and Copper Using Nd: YAG Laser Welding", International Conference on Advances in Mechanical Engineering, Surat, Gujarat, 2011, pp. 616-620.

6. Mai T A. and AC Spowage, "Characterisation of dissimilar joints in laser welding of steel-kovar, coppersteel and copper-aluminium", Materials Science and Engineering: A, Vol. 374, no.1-2, pp. 224-233, 2004.

7. Rakesh Chaudhari, Riddhish Parekh, and Asha Ingle," Reliability of Dissimilar Metal Joints using Fusion Welding: A Review", International Conference on Machine Learning, Electrical and Mechanical Engineering, Dubai, 2014, pp. 98-104.

8. Lacki P., K Adamus, K Wojsyk, M Zawadzki, and Z Nitkiewicz, "Modeling of heat source based on parameters of electron beam welding process", Archives of Metallurgy and Materials, Vol. 56, no. 2, pp. 455462, 2011. 